\title{
Rapid one step urine test for human chorionic gonadotrophin in evaluating suspected complications of early pregnancy
}

\author{
J C P Kingdom, Teresa Kelly, A B MacLean, E Jean McAllister
}

\begin{abstract}
Objective-To determine the ability of a sensitive one step urine test to detect human chorionic gonadotrophin in women with suspected complications of early pregnancy.

Design-Test on women presenting to accident and emergency department with gynaecological problems over six months. Results were validated using a quantitative assay for human chorionic gonadotrophin in serum and urine.

Setting-Accident and emergency department and gynaecology wards of a university teaching hospital.

Subjects - 130 unselected women.

Main outcome measures-Detection of human chorionic gonadotrophin by one step test, presence of ectopic pregnancy, and results of quantitative analysis of chorionic gonadotrophin in serum and urine.

Results -79 women had a positive urine test result and 51 a negative result. All 12 women with ectopic pregnancy had a positive test result, although urinary concentration varied from 191 IU/1 to 47800 IU/l. Only one woman, who had a faintly positive result, was found not to be pregnant on subsequent examination. The sensitivity and negative predictive values of the urine test were $100 \%$ respectively. 33 women were sent home from the accident and emergency department with normal clinical findings after a negative urine test result. All these women had undetectable concentrations of chorionic gonadotrophin in matched samples of urine and serum.

Conclusions-A simple, rapid one step test for chorionic gonadotrophin should be available for the initial evaluation of emergency gynaecological problems. The additional cost of the test is offset by not admitting those patients whose clinical findings are normal and who have a negative urine test result and by reducing the number of women requiring quantitative assays of chorionic gonadotrophin.
\end{abstract}

\section{Department of}

Gynaecology, Western

Infirmary, Glasgow

G11 6NT

J C P Kingdom, MRCOG, registrar

Teresa Kelly, MB, senior house officer

A B MacLean, FRCOG, senior lecturer

Department of Biochemistry, Western Infirmary, Glasgow G11 6NT

E Jean McAllister, BSC, principal grade biochemist

Correspondence to: Dr J C P Kingdom, Queen Mother's Hospital, Yorkhill, Glasgow G3 8SH.

BMF 1991;302:1308-11
Chorionic gonadotrophin concentrations in the mously, from as little as $15 \mathrm{IU} / \mathrm{l}$ to $100000 \mathrm{IU} / \mathrm{l}$, presumably reflecting the variable amount of funcserum of women with ectopic pregnancy vary enor- tional trophoblast tissue present. Thus the only value of this test in ectopic pregnancy is to alert the doctor by reliably recording a positive result, which depends entirely on the sensitivity of the test. A simple, rapid, and sufficiently sensitive urine kit for chorionic gonadotrophin could perhaps reduce the need for inpatient assessment and, at the same time, alert doctors to the possibility of ectopic pregnancy.

We evaluated a sensitive kit for testing urinary concentrations of the hormone (threshold 50 IU/l) with specific reference to detecting ectopic pregnancy in an unselected group of patients presenting to the accident and emergency department of a university teaching hospital.

\section{Subjects and methods}

Women were entered into the study on presentation to the accident and emergency department (through either self referral or their general practitioner), with lower abdominal pain or abnormal vaginal bleeding and a suspicion of early pregnancy. All such women were seen directly by a senior house officer in gynaecology (often with no previous experience in the specialty) without any prior input by the accident and emergency medical staff. The senior house officer assigned each woman to one of three clinical groups using the following diagnostic criteria.

Threatened abortion-Painless vaginal bleeding after a definite history of amenorrhoea, accompanied by a closed cervix, an enlarged non-tender uterus, and no palpable adnexal mass.

Possible ectopic pregnancy-A history of lower abdominal pain or of irregular vaginal bleeding accompanied by a clinical suspicion of pregnancy-for example, breast tenderness, nausea, or recent unprotected intercourse. (The criteria for this group were deliberately kept broad to emphasise the diverse presentation of ectopic pregnancy to the senior house officers.)

Definite ectopic pregnancy-Sudden severe lower abdominal pain with a clinical suspicion of pregnancy and evidence of shock. Patients in this category were taken directly to theatre from the accident and emergency department. Women in whom the clinical diagnosis was inevitable or incomplete abortion were excluded from the study.

After the women had been assigned to one of the three clinical groups a urine test for chorionic gonadotrophin was performed (Clearview, Unipath, Bedford) in the accident and emergency department. The kit has three windows: a sample window, a result window, and a control window (fig 1). The test is a one step procedure, only requiring five drops of urine to be put on to the sample window. Chorionic gonadotrophin reacts with the specific antibodies in the result window to produce a horizontal blue band. If no hormone is present in the urine sample the result window remains clear. The control window should always develop a blue line, showing that the test is complete and has worked correctly. Urine containing $\geqslant 50 \mathrm{IU} / \mathrm{l}$ of the hormone should produce a definite blue line in the result window. The result was recorded as positive, 


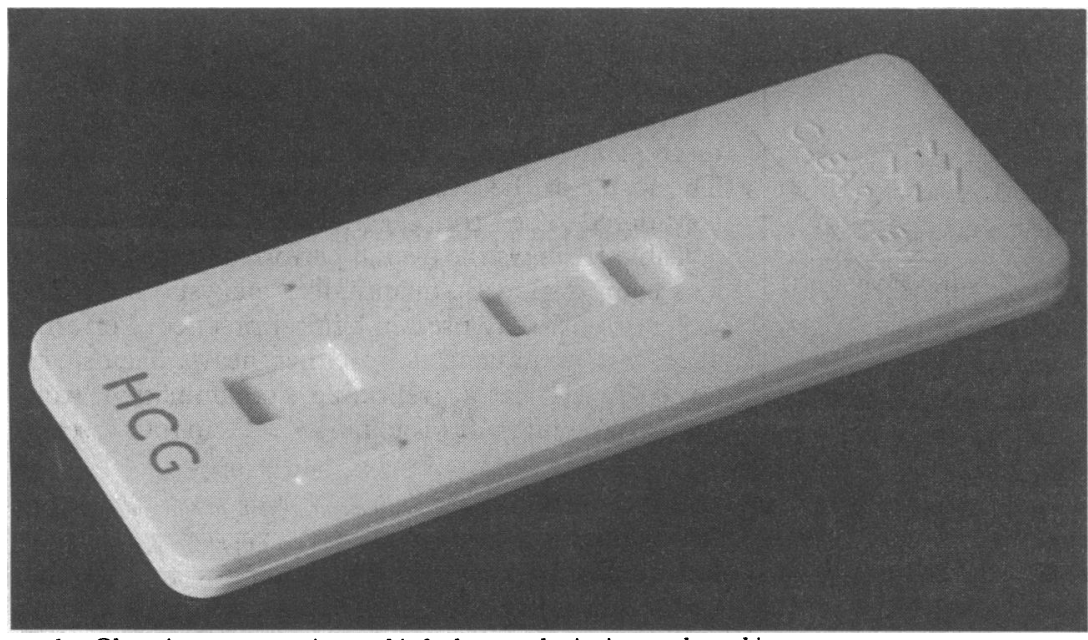

FIG 1-Clearview one step urine test kit for human chorionic gonadotrophin

faint (included as a positive result during analysis), or negative in the clinical notes and on a data collection sheet. A urine dipstick test for protein and blood was also performed.

The urine sample was saved and stored at $-20^{\circ} \mathrm{C}$ before determination of chorionic gonadotrophin concentration (Amerlite HCG 60, Amersham International, Amersham). A matched sample of serum was similarly analysed for the hormone as part of normal clinical practice. The lower limit of detection of the hormone by this method is $2 \mathrm{IU} / 1$ (first international reference preparation 75/537). A cut off point of 5 IU/1 was chosen to indicate a positive result. Analysis of the hormone in both urine and serum was performed blind to the results of the urine test.

All women diagnosed as having a threatened abortion were admitted to the gynaecology ward if their urine test result was positive. The gynaecology senior house officers were, however, allowed to send home any women whom they had assigned to this group but whose urine test result was subsequently found to be negative provided that a reappraisal of their clinical findings was consistent with a diagnosis of dysfunctional uterine bleeding. Similarly, any woman initially assigned to the possible ectopic pregnancy group could be sent home provided that three criteria were fulfilled: firstly, that the clinical findings on abdominal and pelvic examination were normal; secondly, that the result of the urine test for chorionic gonadotrophin was negative; and, thirdly, that the patient could be contacted at home by telephone.

The serum concentration of human chorionic gonadotrophin of any woman sent home from the accident and emergency department with a negative urine test result was checked the next day to exclude a false negative test result.

Pelvic ultrasonography was performed the morning after admission on those women who were admitted to hospital. Women were then reassessed (normally by a registrar or consultant) with the results of this examination and their serum chorionic gonadotrophin concentration, after which they were assigned to one of five management categories: not pregnant, viable intrauterine pregnancy, possibly viable intrauterine pregnancy, non-viable intrauterine pregnancy, or pregnant but no intrauterine gestation sac found.

Among women diagnosed as being pregnant but with no gestation sac, those in whom serial serum samples showed a fall in chorionic gonadotrophin concentration in the absence of abdominal pain or pelvic tenderness were classified as having had a complete abortion; those women with a static or rising serum chorionic gonadotrophin concentration with pain or suspicious adnexal mass had laparoscopy and subsequent laparotomy if an ectopic pregnancy or intraperitoneal blood were seen. All cases of ectopic pregnancy were confirmed by histological examination of the resected fallopian tube.

When the viability of an intrauterine pregnancy was doubtful and vaginal bleeding had settled the woman was allowed home and a repeat ultrasonography arranged one week later as an outpatient.

\section{Results}

One hundred and thirty women were entered into the study. Five women were assigned to the definite ectopic pregnancy group and taken to theatre, where a tubal ectopic pregnancy was removed in each case; all had had a positive urine test result in the accident and emergency department. Figures 2 and 3 show the results of the tests and ultrasonography and subsequent clinical outcomes in those women in whom the initial diagnosis was threatened abortion and possible ectopic pregnancy.

\section{WOMEN WITH POSITIVE URINE TEST RESULT}

Seventy nine women had a positive urine test result. No intrauterine pregnancy was visualised in seven women in the threatened abortion group (fig 2). The presence of chorionic gonadotrophin was confirmed by quantitative methods (in both serum and urine) in six of these women and complete abortion was finally diagnosed in each after hormone concentrations fell and there were no clinical findings suspicious of ectopic pregnancy. The seventh woman was subsequently shown not to be pregnant (urine and serum chorionic gonadotrophin concentration $<2 \mathrm{IU} / \mathrm{l}$ ). She was one of only six women whose urine test result was recorded as faint during the study. The urine concentrations of chorionic gonadotrophin were measured in four of the five remaining women $(20,30,113,214 \mathrm{IU} / \mathrm{l})$.

Nine women in the possible ectopic pregnancy group had no detectable intrauterine pregnancy on ultrasonography (fig 3). Seven of this group were found to have a tubal ectopic pregnancy. There were no false positive urine test results in this group.

Table I shows the urine and serum concentrations of human chorionic gonadotrophin in the 12 women with tubal ectopic pregnancies. There was over a 1000 -fold difference between the lowest (19 IU/1) and highest (47800 IU/l) urine concentrations in this group, yet all these women had a positive urine test result.

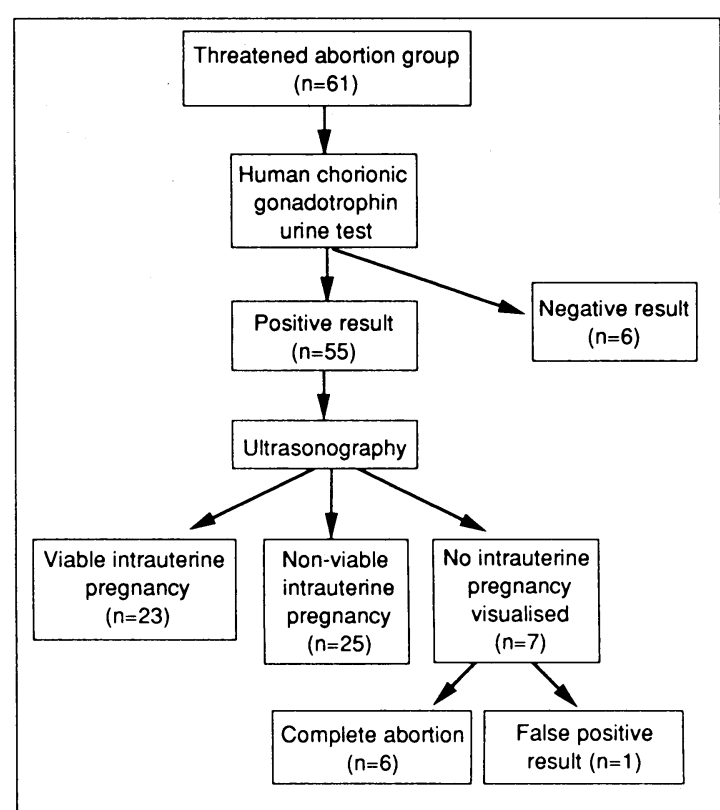

FIG 2-Outcome in women in whom initial diagnosis was threatened abortion 


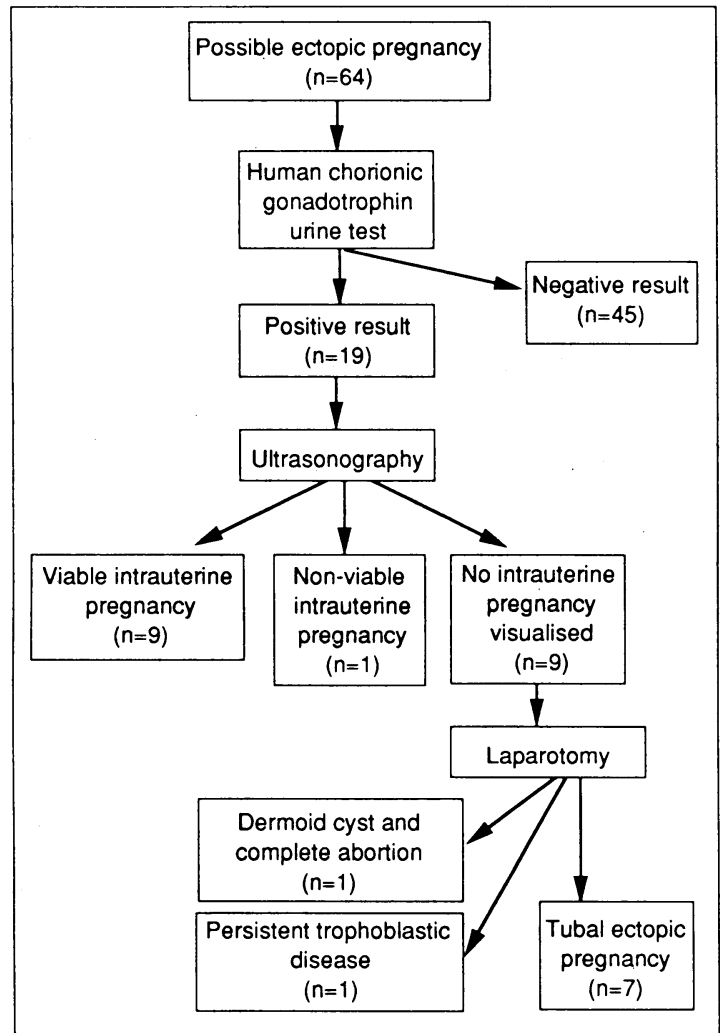

FIG 3-Outcome in women in whom initial diagnosis was possible ectopic pregnancy

\section{WOMEN WITH NEGATIVE URINE TEST RESULT}

Fifty one women had a negative urine test result (figs 2 and 3). Thirty three of these were sent home from the accident and emergency department: all six in the threatened abortion group, and 27 of the 45 in the possible ectopic pregnancy group. In the absence of pain or abnormal pelvic findings these women were deemed to have a dysfunctional menstrual cycle.

Of the 18 women who were admitted (all from the possible ectopic pregnancy group), three required a laparotomy on clinical grounds; two were found to have torted ovarian cysts and the other a ruptured corpus luteal cyst. The results of pelvic ultrasonography were normal in the remaining 15 women in this group. A presumptive diagnosis of pelvic inflammatory disease was made in eight, and oral antibiotics were prescribed, though no pathogenic organisms (including chlamydia) were identified from endocervical swab cultures in any woman. Each settled with bed rest before discharge.

Quantitative analysis of chorionic gonadotrophin in the serum and urine of all 51 women with a negative urine test result showed undetectable concentrations (in both serum and urine) in 50. A serum concentration of $17 \mathrm{IU} / \mathrm{l}$ was obtained (from a very haemolysed specimen) in one woman, but her urine sample had no detectable human chorionic gonadotrophin. A nonhaemolysed sample of serum obtained the next day gave a negative result for the hormone. The haemolysed serum sample was retested after this discrepancy was discovered, giving a result of $<2$ IU/l. The result of the urine test in this woman was thus considered to be a true negative result.

Table II shows the overall performance of the urine test compared with quantitative analysis in serum, which is currently used in clinical practice. Performance was uninfluenced by either heavy haematuria $(\geqslant 2+$ in 34 cases, reflecting contamination from vaginal bleeding), or proteinuria ( $\geqslant 2+$ in four cases).

TABLE II-Performance of Clearview urine test for chorionic gonadotrophin in women with emergency gynaecological problems

\begin{tabular}{lccc}
\hline $\begin{array}{l}\text { Result of } \\
\text { Clearview } \\
\text { urine test }\end{array}$ & \multicolumn{3}{c}{ Serum chorionic gonadotrophin } \\
\cline { 2 - 4 } & $\geqslant 5$ IU/1 (positive) & $<5$ IU/l (negative) & Total \\
\hline $\begin{array}{l}\text { Positive } \\
\text { Negative }\end{array}$ & 78 & 1 & 79 \\
\hline Total & 78 & 51 & 51 \\
\hline $\begin{array}{l}\text { Sensitivity }=100 \%, \\
\text { negative predictive value }=100 \% .\end{array}$ & & & 130 \\
\hline
\end{tabular}

To investigate the relation between the concentration of chorionic gonadotrophin and urine concentration, the ratio of urine to serum concentrations of human chorionic gonadotrophin was plotted against creatinine concentrations in urine. A significant linear relation was obtained $\left(R^{2}=0.59 ; p<0.001\right)$ such that above a urine creatinine concentration of $10 \mathrm{mmol} / \mathrm{l}$ the ratio was greater than 1 .

\section{Discussion}

Our study suggests that the urine test kit cán reliably detect chorionic gonadotrophin in an unselected group of women attending an accident and emergency department. In the context of either abnormal vaginal bleeding or abdominal pain, a positive result will alert the doctor to a complication of early pregnancy, including ectopic pregnancy. Conversely, a negative result reliably excluded pregnancy, and as such admission can be guided by clinical findings alone (for example, a pelvic mass): those with normal pelvic findings need not necessarily be admitted.

A quarter of the women in our study were sent home from the accident and emergency department with a negative urine test result, none of whom had human chorionic gonadotrophin detected by quantitative methods (negative predictive value $100 \%$ ). This reduction in the number of emergency admissions shows the potential cost effectiveness of such a test when available as part of the initial gynaecological assessment. Furthermore it guides the junior gynaecologist in training to make good management decisions in the accident and emergency department-where an in-

TABLE I-Results of tests and examination in women with proved ectopic pregnancy

\begin{tabular}{|c|c|c|c|c|c|c|c|}
\hline Case No & $\begin{array}{l}\text { Length of } \\
\text { amenorrhoea } \\
\text { (weeks) }\end{array}$ & $\begin{array}{l}\text { Diagnosis at } \\
\text { admission }\end{array}$ & $\begin{array}{l}\text { Result of one } \\
\text { step urine test } \\
\text { for chorionic } \\
\text { gonadotrophin }\end{array}$ & $\begin{array}{c}\text { Urine } \\
\text { chorionic } \\
\text { gonadotrophin } \\
(\mathrm{IU} / \mathrm{l})\end{array}$ & $\begin{array}{c}\text { Urine } \\
\text { creatinine } \\
(\mathrm{mmol} / \mathrm{l})\end{array}$ & $\begin{array}{c}\text { Serum } \\
\text { chorionic } \\
\text { gonadotrophin } \\
(\text { IU/l) }\end{array}$ & $\begin{array}{c}\text { Result of } \\
\text { ultrasonography }\end{array}$ \\
\hline 1 & 5 & definite ectopic & positive & 16600 & $6 \cdot 8$ & 7417 & not done \\
\hline 2 & 1 & definite ectopic & positive & 895 & 19 & 384 & not done \\
\hline 3 & 7 & definite ectopic & positive & 180 & 8 & 464 & not done \\
\hline 4 & 8 & definite ectopic & positive & & & $>20000$ & not done \\
\hline 5 & 3 & definite ectopic & positive & 1993 & $11 \cdot 7$ & 756 & not done \\
\hline 6 & 5 & possible ectopic & positive & & & 404 & no intrauterine pregnancy seen \\
\hline 7 & 10 & possible ectopic & positive & 107 & 0.4 & 253 & no intrauterine pregnancy seen \\
\hline 8 & 8 & possible ectopic & positive & 47800 & $0 \cdot 9$ & $>20000$ & left adnexal mass \\
\hline 9 & 9 & possible ectopic & positive & 1300 & 6 & 4626 & right adnexal mass \\
\hline 10 & 2 & possible ectopic & positive & 19 & $10 \cdot 4$ & 43 & right adnexal mass \\
\hline 11 & ? & possible ectopic & positive & 1363 & $13 \cdot 2$ & 1050 & no intrauterine pregnancy seen \\
\hline 12 & 2 & possible ectopic & positive & 453 & $16 \cdot 6$ & 115 & no intrauterine pregnancy seen \\
\hline
\end{tabular}


appropriate discharge could, in the case of a missed ectopic pregnancy, be potentially disastrous. We now use the test kit in the accident and emergency department whenever women present with emergency gynaecological problems. New senior house officers have found the test helpful in learning how to manage women with such problems, and our impression is that fewer women have been admitted in whom the final diagnosis was dysfunctional uterine bleeding.

A further aspect of the cost effectiveness of using a sensitive urine test for human chorionic gonadotrophin is that subsequent confirmation of pregnancy by measuring serum concentrations becomes unnecessary for most inpatients. In our study 58 patients $(60 \%$ of the 97 admitted) from the threatened abortion and possible ectopic pregnancy groups had an intrauterine pregnancy localised by ultrasonography. A decision on management of these 58 did not require a quantitative measurement of human chorionic gonadotrophin. We now manage women with possibly viable intrauterine pregnancy by discharging them if or when any vaginal bleeding has stopped and repeating ultrasonography one week later rather than by performing serial measurements of chorionic gonadotrophin as an inpatient.

Chorionic gonadotrophin concentrations should be measured if no intrauterine pregnancy has been visualised by ultrasonography. ${ }^{3}$ The results (especially in serial samples) will help distinguish complete abortion from a relatively asymptomatic ectopic pregnancy. This practice is essential as, even with considerable expertise, a positive identification of an ectopic pregnancy (demonstration of an extrauterine fetus by ultrasonography) can at present be made in only about $9 \%$ of cases. ${ }^{+}$

It is particularly encouraging that a positive urine test result was recorded in all 12 women with an ectopic pregnancy (table). The lowest urine human chorionic gonadotrophin concentration in these women was $19 \mathrm{IU} / \mathrm{l}$, which shows the degree of sensitivity needed from a urine test for human chorionic gonadotrophin under these circumstances. Norman et al evaluated the performance of the Tandem Icon kit in a selected group of 175 patients in whom ectopic pregnancy was suspected. ${ }^{5}$ Although their kit detected all 95 cases of ectopic pregnancy, the kit has three separate steps and is more complex to use than the Clearview urine test that we used.

A direct relation between serum and urine chorionic gonadotrophin concentration has been claimed, though varying urine concentrations will probably influence such an association. We found that the ratio of urine to serum concentration increases with urine creatinine concentration and that at a creatinine concentration above $10 \mathrm{mmol} / \mathrm{l}$ the urine chorionic gonadotrophin concentration is likely to be higher than that in the serum. This is important because a woman who is in pain with an ectopic pregnancy may be less inclined to drink, have more concentrated urine, and thus higher concentrations of chorionic gonadotrophin in her urine than in her serum. A qualitative test for human chorionic gonadotrophin in urine is likely to perform well under such circumstances.

One possible drawback of a sensitive urine test for chorionic gonadotrophin may be the unnecessary detection of early complete abortion (often referred to as biochemical pregnancy), which might otherwise be regarded as a heavy period by the patient. Wilcox et al purposefully identified 43 clinically unrecognised pregnancies among 552 menstrual cycles in women attempting to conceive. ${ }^{6}$ The potentially adverse psychological sequelae of early pregnancy loss should not be forgotten, ' and it is perhaps reassuring that only six women were deemed to have had a complete abortion in our study.

In conclusion, we have shown the ability of a sensitive one step urine test to reliably detect chorionic gonadotrophin in an unselected group of women presenting to an accident and emergency department with potential complications of early pregnancy. The availability of such a test in these circumstances will alert the assessing doctor to the possibility of ectopic pregnancy and also provide a framework for a more rational subsequent management of those deemed not to be pregnant.

We thank Dr R Brocklehurst of Unipath for his help in the design of the study and for providing the Clearview urine test kits.

1 Tindall VR. Feffcoate's principles of gynaecology. 5th ed. London: Butterworths, 1987:212.

2 DiMarchi JM, Kosasa TS, Hale RW. What is the significance of the human chorionic gonadotropin value in ectopic pregnancy? Obstet Gynecol 1989;74 $851-5$.

3 Shepherd RW, Patton PE, Novy MJ, Burry KA. Serial $\beta$-hCG measurements in the early detection of ectopic pregnancy. Obstet Gynecol 1990;75:417-20.

4 Bateman BG, Nunley WC Jr, Kolp LA, Kitchin JD III, Felder R. Vagina sonography findings and hCG dynamics of early intrauterine and tubal pregnancies. Obstet Gynecol 1990;75:421-7.

5 Norman RJ, Buck RH, Rom L, Joubert SM. Blood or urine measurement of human chorionic gonadotropin for detection of ectopic pregnancy? A comparative study of quantitative and qualitative methods in both fluids. Obstet Gynecol 1988;71:315-8.

6 Wilcox AJ, Weinberg CR, O'Connor JF, Baird DD, Schlatterer JP, Canfield $\mathrm{RE}$, et al. Incidence of early loss of pregnancy. $N$ Engl $\mathcal{f}$ Med 1988;319. RE, et al.

7 Turner $M J$, Flannelly GM, Wingfield $M$, Rasmussen $M J$, Ryan R, Cullen $S$ et al. The miscarriage clinic: an audit of the first year. Br $\mathcal{F}$ Obstet Gynaecol 1991;98:306-8.

(Accepted 10 April 1991)
My Uncle Roland had very bad asthma and this upset his professional routine. He used to do his visiting in the middle of the night and his patients might wake up in the morning to find little notes saying: "Called to see you at 245 , but found you asleep" pinned to their doors. Conversely, he himself would fall asleep in the middle of talking to you and would do so even when discussing patients with his assistant. He used to make his patients presents of groceries and vegetables if he thought they needed them and would then ask his mother to foot the bills. As a result of this he got nothing in her will, since her legal adviser persuaded her that he had had "ten times as much as anybody else already."

Unfortunately there was a dark side to all this. Probably because of his asthma he became addicted to morphine and very nearly got himself struck off the Register. He was involved in a fatal road accident and also in a case relating to the supply of dangerous drugs. But everyone was always ready to help him when possible because he was well liked, and he survived all his troubles, if not quite unscathed, then certainly without legal or social consequences. His patients made allowances for his lapses. Fifty years later, one of them told my son that Roland was "drunk" when he examined him. "But then," said the patient in generous extenuation, "they all were."

From Not a Proper Doctor by David Sinclair. Published under the BMY's Memoir Club imprint. ISBN 072790279 2. Price: Inland £14.95; abroad $£ 18.50$. BMA members: Inland $£ 13.95$; abroad $£ 17.50$. 